\title{
Impact of local policies on transport pollutant emission
}

\author{
L. Gambini-Rossano, G. Passerini \& S. Tascini \\ Dipartimento di Energetica, Università Politecnica delle Marche, Italy
}

\begin{abstract}
A proper planning of mobility can reduce air pollution due to road traffic. A crucial role, also aiming to improve sustainability, is played by the local Public Policies. Public Policies and initiatives can facilitate air pollution control, but an environmental consciousness has to be spread too. According to this principle, Ancona Provincial Authority is aiming at minimising the environmental impact of road traffic by persuading commuters to switch to public transportation systems.

The aim of our work is the evaluation of improvements of air quality in a set of scenarios that could take place according to the Provincial Authority Policies. The study has been developed for the whole Ancona Province considering the exurban mobility network. The Province Offices provided data about the present passenger mobility scenario and the possible scenario based on an implemented public transportation system better responding to the local demand. Tangible reduction of the emissions from transportation is generally expected.

The results are summarized by two main indices: the load of pollutants for each arc supports the decision-making process on the validity of the planned scenario, while the load of pollutants per person for each arc offers a social responsibility index to help the Public Administration to implement a sustainable and responsible culture in the citizens.
\end{abstract}

\section{Introduction}

In November 2003, the local Authorities of the Ancona Province approved [1] the "Area Scheme" (PdB) for the "Local Public Transportation system" (TPL) which became the planning tool for public transportation for the next nine years [2]. This document has been prepared within the framework of the "Regional 
Scheme for the Local Public Transportation system" (PRTPL) i.e. the tool of the Marche Regional Authority that provides the main guidelines to be followed by the local Authorities to reorganize the Local Public Transportation System (TPL). Two main targets of the PRTPL aim to define functional areas and to plan an integrated network for the TPL [2].

Another important public planning document is the "Programme of Urban and Sustainable Development in the Territory” (PRUSST), which highlights the objective to offer a high quality and competitive public transportation system in order to subtract traffic shares to the private transportation system [2]. Reducing journey duration and traffic congestions become priorities also to reduce pollutant emissions in atmosphere [3]. To act these main concerns it is necessary to reorganize the transportation system mainly avoiding overlaps of train, bus and car routes. The objectives of the $\mathrm{PdB}$ are to switch commuters from private cars to public transports, to balance the use of trains and coaches, and to improve environmental quality. The actions planned with the PdB will be reassessed after three years (November 2006) according to the evaluation of mid-term results.

In the framework of a pilot project established by the Environmental Ministry, the Marche Regional Authority, the Environmental Authority of the Ancona Province and other Local Authorities [3], our research group was asked for the assessment of pollutant emissions due to road traffic along the exurban road network. The pilot project aims to apply the Strategic Environmental Assessment (SEA)-ex the European directive 2001/42-to the transport sector and specifically to the PdB of the Ancona Province. In particular, this work supports the evaluation of the effects of revised coach scheduling and paths including the effects on private car use.

In fact, to achieve the goal of a significant reduction of overall pollutant emissions, the authorities needed a precise assessment of emissions in different scenarios. Moreover, a set of significant indexes describing the comparative influence of diverse measures was considered a plus.

Local Offices of the Province have supplied commuter fluxes, which they had previously computed by an appropriate model: PT Vision Visum 7.5.

\section{The evaluation of the $\mathrm{NO}_{\mathrm{X}}$ and $\mathrm{CO}$ emissions in different scenarios}

\subsection{Significant indexes}

The evaluation of $\mathrm{NO}_{\mathrm{X}}$ and $\mathrm{CO}$ emissions has been carried out, at morning rush hours, namely between 7am and 9am on a weekday. In a first step, the roads of Ancona province have been split in arcs connecting nodes. Each arc was characterized by length, number of coach rides coach, number of coach passengers, number of cars, number of car passengers, and nominal speed.

Two main indexes have been calculated: the overall load of pollutants per arc and the load of pollutants per person per arc. The latter parameter was separately evaluated for both private transport and public transport. Total loads over the 
exurban road network-but the A14 highway-have been compared referring to the present and the scenario of the PdB.

The possibility to compare loads of pollutants for each arc allows the public Authorities to understand which arc needs to be kept under attention from an air quality point of view and how much these can be improved by a public transport system revision. It supports the decision-making process on the validity of the planned scenario.

The load of pollutants per person for each arc offers the local Authorities an opportunity to involve and make conscious commuters, to further stimulate them to switch to public transport. This index is a kind of social responsibility index that could respond to the necessity of creating a sustainable and responsible culture in citizens.

Table 1: $\quad$ Car park: fuel and legislation classes considered.

\begin{tabular}{|c|c|c|c|c|c|c|}
\cline { 3 - 7 } \multicolumn{2}{c|}{} & \multicolumn{6}{c|}{ Legislation Class } \\
\hline \multirow{2}{*}{ Fuel } & Displacem. & $\begin{array}{c}\text { Euro } \\
\text { I }\end{array}$ & $\begin{array}{c}\text { Euro } \\
\text { II }\end{array}$ & $\begin{array}{c}\text { Euro } \\
\text { III }\end{array}$ & $\begin{array}{c}\text { Euro } \\
\text { IV }\end{array}$ & $\begin{array}{c}\text { NO } \\
\text { Euro }\end{array}$ \\
\hline Gasoline & up to 1400 & 90059 & 130313 & 93894 & 9736 & \\
\hline Gasoline & $1401-2000$ & 32610 & 33261 & 19175 & 2016 & \\
\hline Gasoline & over 2000 & 853 & 2478 & 3306 & 533 & \\
\hline Gasoline or LPG & up to 1400 & 3448 & 3012 & 408 & 7 & 9876 \\
\hline Gasoline or LPG & $1401-2000$ & 5985 & 2714 & 427 & 10 & 9664 \\
\hline Gasoline or LPG & over 2000 & 59 & 82 & 23 & 3 & 308 \\
\hline Gasoline or LNG & up to 1400 & 7908 & 9091 & 2284 & 46 & 15113 \\
\hline Gasoline or LNG & $1401-2000$ & 6485 & 6462 & 4206 & 402 & 8475 \\
\hline Gasoline or LNG & over 2000 & 24 & 36 & 12 & 5 & 120 \\
\hline Diesel & up to 1400 & 16 & 311 & 21220 & 6373 & 2103 \\
\hline Diesel & $1401-2000$ & 9970 & 63013 & 87515 & 4702 & 12459 \\
\hline Diesel & over 2000 & 3636 & 13842 & 19247 & 488 & 8697 \\
\hline
\end{tabular}

\begin{tabular}{|c|c|c|c|c|c|c|}
\cline { 3 - 7 } \multicolumn{2}{c|}{} & \multicolumn{5}{c|}{ Legislation Class } \\
\hline \multirow{2}{*}{ Fuel } & Displacem. & $\begin{array}{c}\text { ECE } \\
\mathbf{1 5 / 0 1}\end{array}$ & $\begin{array}{c}\text { ECE } \\
\mathbf{1 5 / 0 2}\end{array}$ & $\begin{array}{c}\text { ECE } \\
\mathbf{1 5 / 0 3}\end{array}$ & $\begin{array}{c}\text { ECE } \\
\mathbf{1 5 / 0 4}\end{array}$ & $\begin{array}{c}\text { PRE } \\
\text { ECE }\end{array}$ \\
\hline Gasoline & up to 1400 & 8454 & 6318 & 7735 & 109911 & 21141 \\
\hline Gasoline & $1401-2000$ & 1314 & 1232 & 1612 & 27955 & 1518 \\
\hline Gasoline & over 2000 & 273 & 237 & 213 & 1429 & 844 \\
\hline
\end{tabular}

\subsection{Vehicle fleets}

The first issue is to collect valid data about the car and coach fleets. The data supplied by the Province Offices, namely number of cars and coach rides per arc, had to be statistically associated to the different types of cars and coaches classified by vehicle fuel, cylinder capacity and legislation class. 
The Italian Automobile Club (ACI) provides up to date data about the national, regional and local fleets [4]. Data have been further elaborated to exclude vehicles classified as "not identified" so to associate proper emission curves. To better represent the fleet running in the territories of the Ancona province, regional data have been used to evaluate the percentage of the different classes to be statistically associated to the arcs.

\subsection{Emission curves}

Emission curves and emission factors adopted to calculate pollutant loads due to traffic are the ones proposed in COPERT III methodology [5]. The development of COPERT III was financed by the European Environment Agency (EEA), in the framework of the activities of the European Topic Centre on Air Emissions to be used for the compilation of CORINAIR emission inventories [5].

In this study, for the class of cars denominated "gasoline or methane" (LNG) the "gasoline or liquefied petroleum gas" (LPG) emission curves have been applied as well. Speeds over various arcs always refer to proper unloadednetwork free speeds.

Table 2: $\quad$ Total $\mathrm{NO}_{\mathrm{X}}$ and Co evaluation; grams.

\begin{tabular}{|c|c|c|}
\hline \multicolumn{3}{|c|}{$\begin{array}{l}\text { Values for the ANCONA PROVINCE 7-9 a.m. } \\
\text { TOTAL PRIVATE AND PUBLIC EXURBAN TRAFFIC }\end{array}$} \\
\hline \multicolumn{3}{|c|}{ NO $_{X}$ EMISSIONS } \\
\hline $\mathrm{TOT} \mathrm{NO}_{\mathrm{X}} \mathrm{PdB}$ & $\begin{array}{l}\mathrm{NO}_{\mathrm{X}} \text { from private traffic } \\
\mathrm{PdB}\end{array}$ & $\begin{array}{l}\mathrm{NO}_{\mathrm{X}} \text { from public coaches } \\
\text { PdB }\end{array}$ \\
\hline 269170.56 & 232235.48 & 36935.08 \\
\hline TOT $\mathrm{NO}_{\mathrm{X}}$ & $\mathrm{NO}_{\mathrm{X}}$ from private traffic & $\mathrm{NO}_{\mathrm{X}}$ from public coaches \\
\hline 304761.49 & 241722.89 & 63038.60 \\
\hline \multicolumn{3}{|c|}{ NO $_{\mathbf{X}}$ Differences PdB-present scenario } \\
\hline NO $_{\mathbf{X}}$ Tot & $\mathrm{NO}_{\mathrm{X}}$ Priv & NO $_{\mathbf{X}}$ Publ \\
\hline-35590.93 & -9487.41 & -26103.52 \\
\hline$-11.68 \%$ & $-3.92 \%$ & $-41.41 \%$ \\
\hline \multicolumn{3}{|c|}{ CO EMISSIONS } \\
\hline TOT CO PdB & $\begin{array}{l}\text { CO from private traffic } \\
\text { PdB }\end{array}$ & $\begin{array}{l}\text { CO from public coaches } \\
\text { PdB }\end{array}$ \\
\hline 759241.48 & 749952.90 & 9288.58 \\
\hline $\mathrm{TOT} \mathrm{NO}_{\mathrm{X}}$ & CO from private traffic & CO from public coaches \\
\hline 794471.38 & 778764.88 & 15706.50 \\
\hline \multicolumn{3}{|c|}{ CO Differences PdB-present scenario } \\
\hline CO Tot & CO Priv & CO publ \\
\hline-35229.90 & -28811.99 & -6417.92 \\
\hline$-4.43 \%$ & $-3.70 \%$ & $-40.86 \%$ \\
\hline
\end{tabular}




\subsection{Traffic fluxes}

The Ancona Province Authority has supplied data about traffic and commuters. Data have been organized to describe the present and the future $(\mathrm{PdB})$ scenarios.

In the VISUM model, graphs of the exurban road network and an origindestination matrix according to the updated 1991 census of Italian Institute of Statistics (ISTAT) for time interval $7 \mathrm{am}$ to 9 am have been entered.

The model ran for the present and future $\mathrm{PdB}$ scenarios to obtain the passenger demand satisfied for each arc. Then for each origin-destination relation, the number of passengers not allocated by the public transportation system have been added to the private traffic. The model has run the private passenger loads to obtain the number of private passengers for each arc. The Ancona Province Offices have calculated the number of cars for each arc according to the statistical relation 1 car for 1.23 passengers [6].

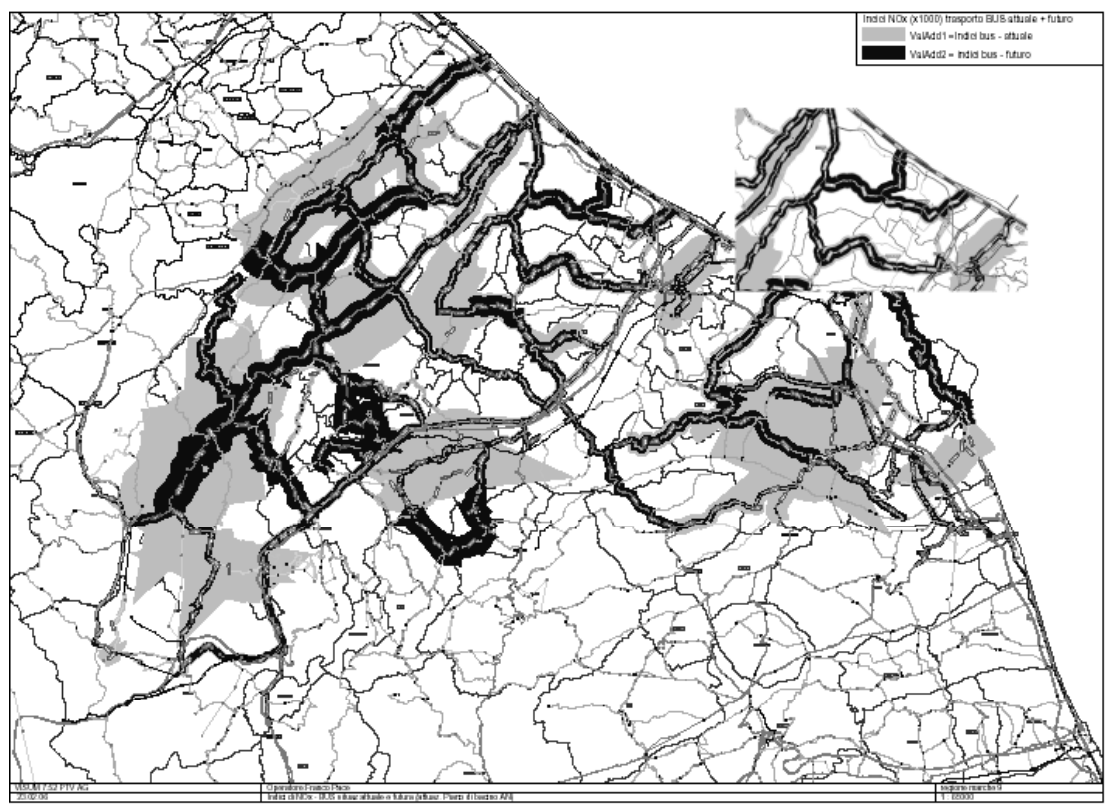

Figure 1: $\quad$ Public present (light grey) and $\mathrm{PdB}$ (dark grey) $\mathrm{NO}_{\mathrm{X}}$ emissions.

\section{Results}

The pollutant loads have been calculated, over the time interval, to obtain the amount of pollutants related to each single arc (grams) and per unit of length $(\mathrm{g} / \mathrm{km})$. The global amount of pollutant over the whole territory has been evaluated (Tab. 2). 


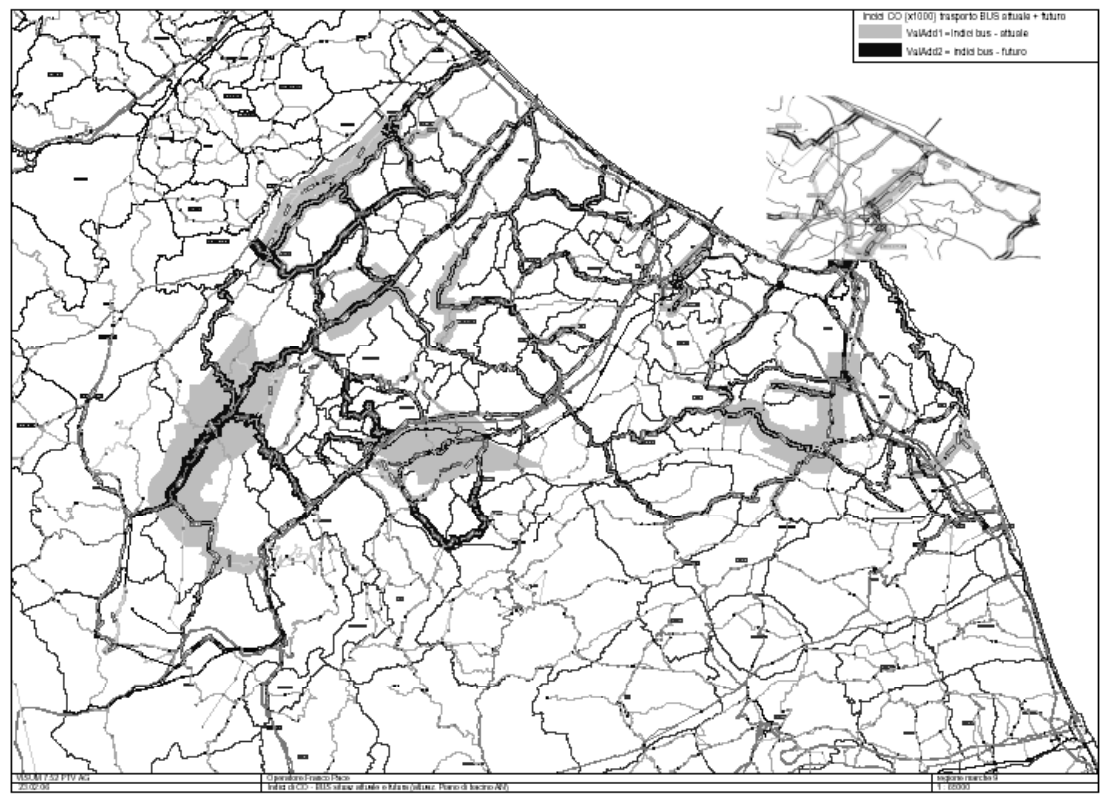

Figure 2: $\quad$ Public present (light grey) and PdB (dark grey) CO emissions.

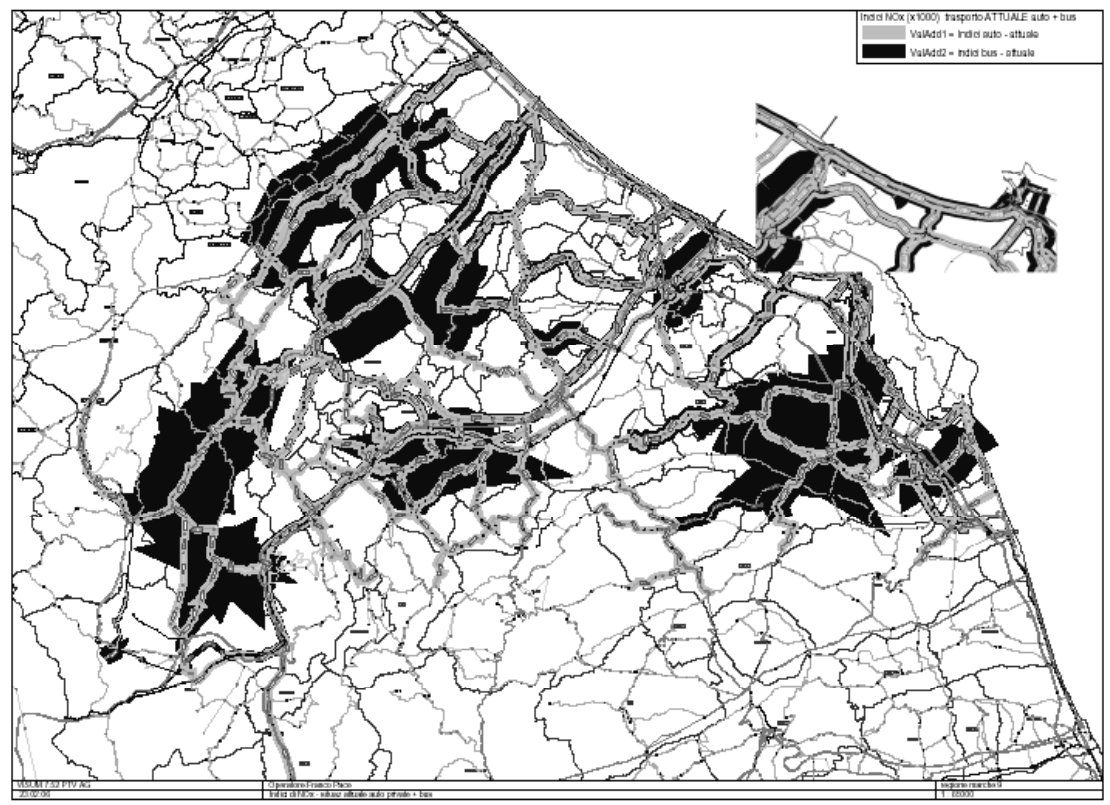

Figure 3: $\quad$ Present private (light grey) and public (dark grey) $\mathrm{NO}_{\mathrm{X}}$ emissions. 


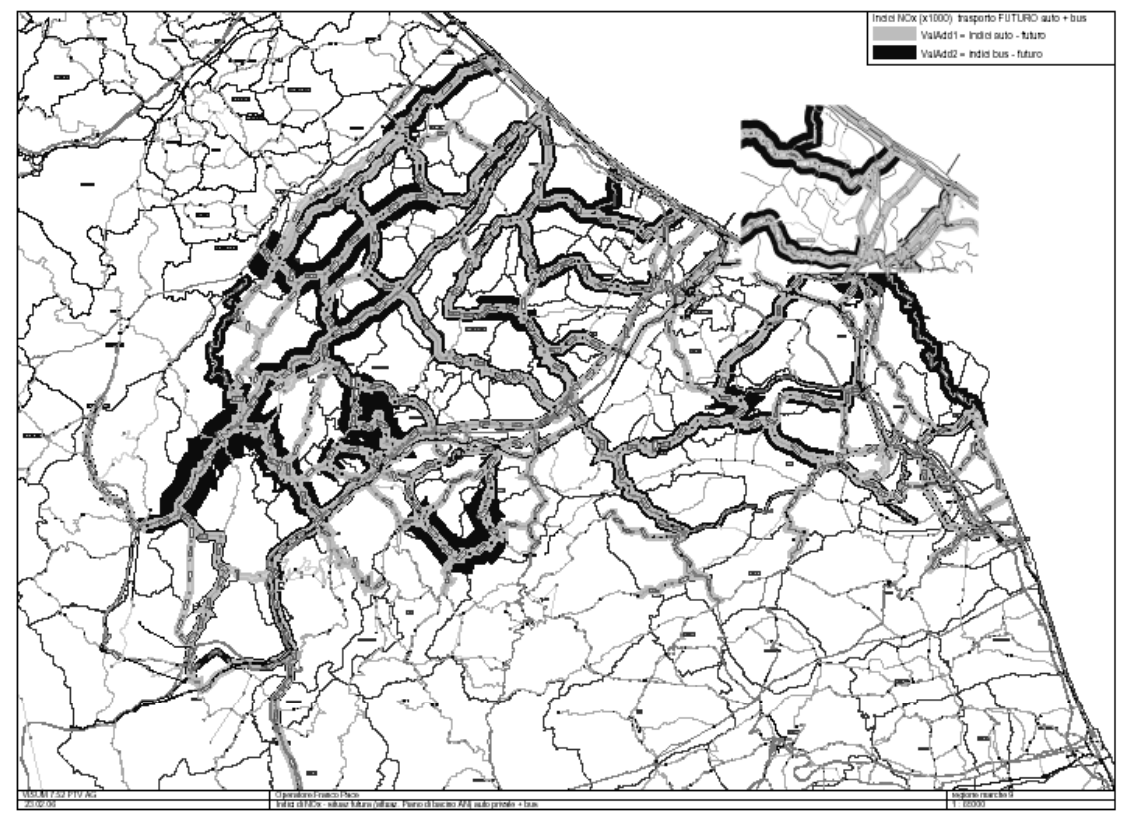

Figure 4: $\quad$ PdB private (light grey) and public (dark grey) $\mathrm{NO}_{\mathrm{X}}$ emissions.

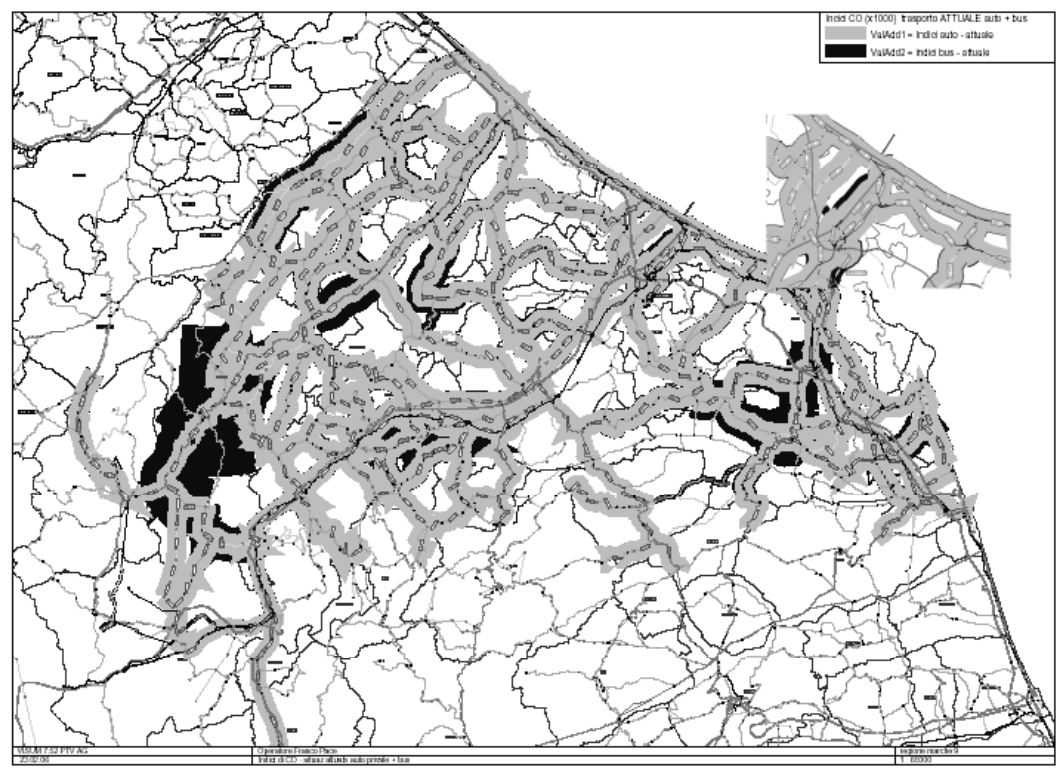

Figure 5: $\quad$ Present private (light grey) and public (dark grey) $\mathrm{CO}$ emissions. 


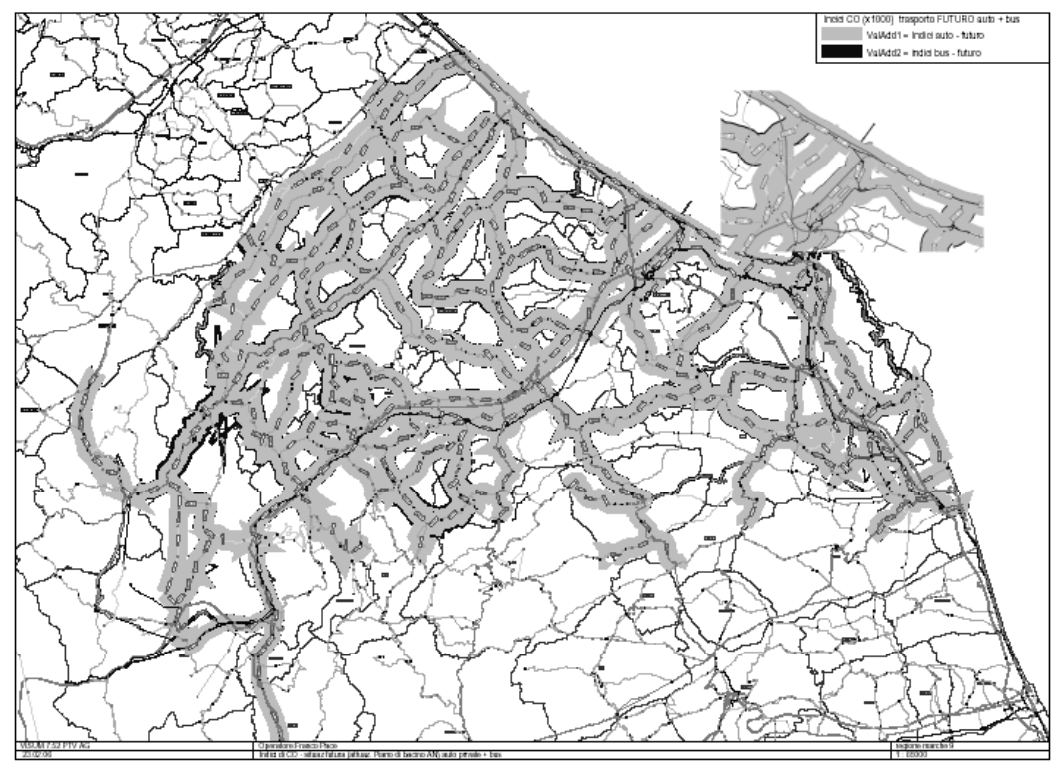

Figure 6: $\quad$ PdB private (light grey) and public (dark grey) evaluation $\mathrm{CO}$ emissions.

A comparison of same arcs and directions between the two scenarios is also possible: 2192 records can be compared with reference to the private and public pollutant loads.

The emissions obtained through our study have been entered back into the Visum model to be represented along the roads. For $\mathrm{NO}_{\mathrm{X}}$ and $\mathrm{CO}$ the following representations (g/km per person over 7-9 a.m.) have been obtained as outlined in Fig 1-6:

a) Public (coaches) present and future PdB evaluation

b) Present private and public (coaches) evaluation

c) Future PdB private and public (coaches) evaluation

\section{Conclusions}

To support further improvements of the Area Scheme for the Local Public Transportation system, an evaluation of $\mathrm{NO}_{\mathrm{X}}$ and $\mathrm{CO}$ emissions pre operam and post operam has been performed. A statistical use of selected data for the car fleet and the coach fleet and the related emission curves from COPERT III has been applied to all commuters moving through the exurban network classified by arcs and nodes.

The amount of pollutants due to the private and public transportation system has been assessed for each arc with reference to the length of the arcs (grams) and to the people transported per unit of length $(\mathrm{g} / \mathrm{km})$. 
In the Ancona province, the implementation of the Area Scheme for the Local Public Transportation system will lead to a reduction of about $12 \%$ of $\mathrm{NO}_{\mathrm{X}}$ emissions and about $4.5 \%$ of $\mathrm{CO}$ emissions, in the $7 \mathrm{am}$ to 9am time interval. Both the amount of pollutants due to the private road traffic and the amount of pollutants due public transportation system will decrease.

\section{Outlook}

Several aspects should be investigated to allow more detailed evaluations. Two main developments can be figured out.

A new assessment shall be done in a scenario including further integrations of local public transportation system with the local railways to better attract present car users.

The actual vehicle speeds, as an alternative to the postulated unloadednetwork free speeds here used, shall be computed to investigate the effects related to traffic jams and rush hour actual conditions.

\section{Acknowledgements}

The authors are grateful to Franco Pace (Ancona Province Authority), Giuseppe Michelangeli (Town Planner) and Massimo Emidi for their help.

This work has been supported by Ministero dell'Istruzione, Università e Ricerca.

\section{References}

[1] Delibera Consiglio Provinciale n. 191 del 24/11/2003

[2] Piano di Bacino del Trasporto Pubblico Locale, Provincia di Ancona

[3] Progetto pilota per la Valutazione Ambientale Strategica del Trasporto Pubblico Locale della Provincia di Ancona, Percorso Metodologico per l'applicazione della Valutazione Ambientale Atrategica, Schede metodologiche documento di lavoro 30 marzo 2005

[4] http://online.aci.it/acinet/cd/datiestatistiche/Frame_Autoritratto_04.asp

[5] Copert III Computer programme to calculate emissions from road transport, methodology and emission factors, v.2.1, 2000

[6] Vademecum della Mobilita' Sostenibile a Cura del Gruppo Mobilità del WWF Lazio 